\title{
Descritores bioquímicos em cultivares de algodoeiro em resposta à inoculação com Colletotrichum gossypii var. cephalosporioides
}

\author{
Fabiana A.C. Silva1, Roseane C. dos Santos ${ }^{2}$, André de Azevedo Neto ${ }^{3}$, Manuela M.C. Granja ${ }^{1}$, Claudia C. \\ F. de Souza ${ }^{1} \&$ Péricles A. Melo Filho ${ }^{1}$
}

${ }^{1}$ Departamento de Agronomia, Universidade Federal Rural de Pernambuco, 52171-900 Recife, PE, Brasil; ${ }^{2}$ Embrapa Algodão, 58107-720, Campina Grande, PB, Brasil; ${ }^{3}$ Laboratório de Bioquímica CETEC, Universidade Federal do Recôncavo da Bahia, 44380-000, Cruz das Almas, BA, Brasil

Autor para correspondência: Fabiana A.C. Silva, e-mail: fabiana.acs@gmail.com

\begin{abstract}
RESUMO
Cinco descritores bioquímicos foram avaliados em algodoeiro infectados com o fungo causador da ramulose visando detectar respostas associadas à infecção. Sementes de quatro cultivares com diferentes níveis de resistência à doença foram semeadas em vasos plásticos, em casa de vegetação. Vinte dias após a emergência, as plântulas foram inoculadas com uma suspensão de 1 x $10^{6}$ conídios/ $\mathrm{mL}$ de Colletotrichum gossypii var. cephalosporioides. Folhas foram coletadas aos 3, 15 e 30 dias após a inoculação e utilizadas para determinação de prolina livre, catalase, peroxidase, carboidratos solúveis e proteínas totais. Verificou-se que os teores de prolina livre, peroxidase e catalase foram discriminadores na reação de plantas infectadas. Estes descritores apresentaram rápida resposta nos primeiros dias após a infecção das plantas, sendo mais expressivo na cv. resistente BRS Antares. Os descritores prolina livre e catalase podem ser utilizados como ferramentas auxiliares na identificação de cultivares resistentes à ramulose nos programas de melhoramento da cultura do algodão.
\end{abstract}

Palavras-chave: Gossypium, enzima, metabólitos, ramulose, resistência.

\section{ABSTRACT \\ Biochemical descriptors of cotton cultivars in response to Colletotrichum gossypii var. cephalosporioides}

Five biochemical descriptors were assessed in cotton plants infected with the ramulosis-causing fungus in order to detect differences associated with the infection. Seeds from four cotton cultivars with different levels of resistance were sown in plastic containers in greenhouse conditions. At 20 days after emergence, plants were inoculated with a suspension at $1 \times 10^{6}$ conidia/mL of Colletotrichum gossypii var. cephalosporioides. Leaves were collected at 3, 15 and 30 days after inoculation and free proline, catalase, peroxidase, soluble carbohydrates and total proteins were determined. Proline, peroxidase and catalase levels discriminated the reaction of infected plants. These descriptors changed soon after infection and the change was more evident in the resistant BRS Antares variety. Free proline and catalase descriptors can be used in the identification of ramulosis-resistant cultivars in cotton breeding programs.

Keywords: Cotton disease, enzyme, metabolites, ramulosis.

$\mathrm{Na}$ lavoura algodoeira, o custo com o controle de plantas invasoras, pragas e doenças chega a $30-40 \%$ do custo total de produção (Freire, 2007). As doenças fúngicas estão entre os principais fatores responsáveis pela queda de produção da cultura. A ramulose, causada por Colletotrichum gossypii South var. cephalosporioides A.S. Costa, é uma das mais prejudiciais, podendo levar a perdas de até $60 \%$ na produção (Freire, 2007). O patógeno infecta as folhas, pecíolos e colmo provocando nanismo e superbrotamento dos ramos, o que prejudica a formação

Parte da Dissertação de Mestrado do primeiro autor. Universidade Federal Rural de Pernambuco. Recife PE. 2008. de maçãs e, conseqüentemente, o rendimento do algodão (Mehta et al., 2005).

Muitas plantas desenvolveram mecanismos de defesa contra perturbações a que são submetidas ao longo do seu ciclo de vida. Algumas delas ativam mecanismos oxidativos buscando eliminar e/ou melhor se adaptar ao agente causador da perturbação, seja ele abiótico ou biótico. Em feijoeiro, Campos et al. (2004), estudando resistência à antracnose em quatro cultivares inoculadas com o fungo Colletotrichum lindemuthiamum observaram, após três dias, grande incremento na atividade das enzimas polifenoloxidase e peroxidase nas cultivares mais resistentes, correlacionando esta enzima com uma resposta sistêmica da planta à infecção pelo patógeno. Dai et al. (1996) investigaram alterações de compostos bioquímicos em cotilédones de cultivares de 
algodoeiro resistente e suscetível a Xanthomonas campestris pv. malvacearum e detectaram altos níveis de flavonóides $10 \mathrm{~h}$ após a inoculação, sendo este acúmulo associado a resposta hipersensitiva ao fungo. Nas plantas resistentes houve atividade de peroxidase e terpenóides após 4 h e $48 \mathrm{~h}$ da inoculação, respectivamente.

A utilização de descritores bioquímicos como ferramenta auxiliar no entendimento das relações patógenohospedeiro tem sido reportada por alguns autores. Scarpari et al. (2005) utilizaram vários descritores bioquímicos para estudar genótipos de Theobroma cacao inoculados com Moniliophtora perniciosa. Estes autores constataram alterações nos níveis de açúcares solúveis, alcalóides, taninos, clorofilas $a$ e $b$, dentre outros, e concluíram que as alterações bioquímicas nos tecidos infectados estão diretamente relacionadas à síntese de etileno pela planta. O objetivo deste estudo foi incrementar o conhecimento relacionado às mudanças bioquímicas que ocorrem no algodoeiro durante a infecção por C. gossypii var. cephalosporioides e definir descritores que possam ser utilizados como indicadores de resistência à ramulose.

Material biológico e condições experimentais - Sementes das cultivares de algodoeiro BRS Antares (Resistente), BRS Cedro (Moderadamente Resistente), BRS 187 8H (Moderadamente suscetível) e CNPA Precoce I (Suscetível) (Mehta et al., 2005; Zandoná et al., 2006) foram cultivadas em vasos plásticos $(5 \mathrm{Kg})$, contendo solo esterilizado e fertilizado de acordo com as necessidades da cultura. $\mathrm{O}$ experimento foi conduzido em casa de vegetação do Departamento de Agronomia (DEPA-UFRPE) nos meses de Julho e Agosto de 2007. Aos 20 dias após a emergência as plântulas foram inoculadas via pulverização com $1 \mathrm{~mL}$ de uma suspensão de $1 \times 10^{6}$ conídios $/ \mathrm{mL}$ de $C$. gossypii var. cephalosporioides $(\mathrm{Cgc})$, obtido da micoteca do Laboratório de Fitopatologia do DEPA. A pulverização foi realizada nas folhas do terço médio inferior, constituindo o tratamento inoculado. Para o tratamento controle (plantas não inoculadas $\mathrm{com}(\mathrm{gc}$ ), as plantas receberam apenas água destilada autoclavada. Após a inoculação, as plântulas foram submetidas à câmara úmida por $72 \mathrm{~h}$ e aos três dias após a inoculação (d.a.i.) coletou-se a primeira amostra de folhas de cada cultivar, sem a presença de sintomas característicos da ramulose, para a realização dos testes bioquímicos. As coletas seguintes ocorreram aos 15 e 30 d.a.i., também assintomáticas.

Análises bioquímicas - Os extratos enzimáticos foram obtidos a partir da maceração de $1 \mathrm{~g}$ de folhas frescas em $10 \mathrm{~mL}$ de tampão fosfato (Fosfato monobásico $100 \mathrm{mM}$, EDTA 0,1 mM, pH 7.0). O macerado foi filtrado em tecido, centrifugado a $14.000 \mathrm{rpm} \mathrm{a} 4^{\circ} \mathrm{C}$ por $15 \mathrm{~min}$. e o sobrenadante transferido para novos tubos que foram mantidos a $-80^{\circ} \mathrm{C}$ para posterior utilização (Campos et al., 2004). Os ensaios em branco foram realizados utilizando-se apenas tampão fosfato sem a presença dos extratos enzimáticos. Todas as análises foram realizadas por meio de espectrofotometria (Fenton).

Carboidratos solúveis - Para este composto orgânico empregou-se o método fenol-sulfúrico (Dubois et al., 1956) com modificações. Para cada amostra de $20 \mu \mathrm{L}$ do extrato enzimático, foi adicionado $480 \mu \mathrm{L}$ de tampão fosfato, 500 $\mu \mathrm{L}$ de fenol $5 \%$ e $2,5 \mathrm{~mL}$ de ácido sulfúrico concentrado seguindo-se de rápida agitação em vortex. A leitura das amostras foi feita a $490 \eta \mathrm{m}$ e a curva padrão foi preparada com D-glicose $0,01 \%(\mathrm{p} / \mathrm{v})$ e utilizada para comparação com as absorbâncias obtidas. Os resultados foram expressos em $\mu \mathrm{M}$ de carboidratos solúveis /g de matéria fresca.

Proteínas totais - Para esta análise as amostras foram diluídas 20 vezes. Para tanto tomou-se uma alíquota de 20 $\mu \mathrm{L}$ e $480 \mu \mathrm{L}$ de tampão fosfato seguindo-se de agitação. Em tubos de ensaio de $15 \mathrm{~mL}$ depositou-se $100 \mu \mathrm{L}$ de cada amostra diluída juntamente com $1 \mathrm{~mL}$ do Reagente de Bradford (Bradford, 1976). Após 15 min procederamse as leituras a $595 \eta \mathrm{m}$. As absorbâncias obtidas foram comparadas com a curva padrão (solução estoque de albumina bovina $-1 \mathrm{mg} / \mathrm{mL}$ ) e os dados expressos em $\mu \mathrm{M}$ de proteínas totais /g de matéria fresca.

Prolina livre - Adicionou-se 1,0 mL do extrato enzimático em tubos de ensaio de $15 \mathrm{~mL}$, rosqueáveis, contendo 1,0 mL de ninhidrina ácida e 1,0 mL de ácido acético glacial concentrado (Bates et al., 1973). Os tubos foram acondicionados em água, a $100{ }^{\circ} \mathrm{C}$, por $1 \mathrm{~h}$. A reação foi interrompida colocando-se os tubos em banho-maria a 2 ${ }^{\circ} \mathrm{C} / 30 \mathrm{~min}$. Em seguida, uma alíquota de 2,0 mL de tolueno foi adicionada ao tubo sob agitação por $15 \mathrm{~s}$. A fase aquosa foi recuperada e submetida à leitura a 520 ๆm. Os valores obtidos foram comparados com a curva padrão de prolina $(0,0115 \mathrm{~g}$ de prolina em um volume final de $100 \mathrm{~mL}$ com água deionizada) e os resultados expressos em $\mu \mathrm{M}$ de prolina /g de matéria fresca

Catalase - Para análise desta enzima pré-aqueceu-se o tampão fosfato $(1,39 \mathrm{~mL})$ por $20 \mathrm{~min}$ a $30^{\circ} \mathrm{C}$. A seguir, adicionou-se $50 \mu \mathrm{L}$ do extrato enzimático e $60 \mu \mathrm{L}$ de peróxido de hidrogênio (500 mM) (Beers \& Sizer, 1952). Após agitacão em vortex realizaram-se duas leituras a $240 \eta \mathrm{m}$, sendo uma aos $15 \mathrm{~s}$ e outra a $60 \mathrm{~s}$. Para cálculo desta enzima utilizaram-se as diferenças entre as médias. Uma unidade de atividade foi definida como a quantidade de enzima que causou o aumento de 0,001 unidade de absorbância por minuto nas condições utilizadas no experimento.

Peroxidase - Nesta análise utilizou-se $1,5 \mathrm{~g}$ de folha macerada em nitrogênio liquido. Ao macerado acrescentouse $4 \mathrm{~mL}$ de solução tampão composta por acetato de sódio $(0,1 \mathrm{mM} / \mathrm{pH} 7,0)$, ácido acético glacial $(0,1 \mathrm{M})$, EDTA (1 $\mathrm{mM}$ ) e $1 \%(\mathrm{v} / \mathrm{v})$ de polivinilpirrolidona (PVP). As amostras foram centrifugadas a $14.000 \mathrm{rpm}$ por $25 \mathrm{~min}\left(4^{\circ} \mathrm{C}\right)$ e o 
sobrenadante transferido para novos tubos e armazenado a $-80^{\circ} \mathrm{C}$.

Para a quantificação desta enzima utilizou-se a metodologia descrita em Dann \& Deverall (2000). Ao tubo de ensaio adicionou-se $25 \mu \mathrm{L}$ de guaiacol $(0,02 \mathrm{M}), 1,0$ $\mathrm{mL}$ do tampão acetato $(100 \mathrm{mM})$ e $250 \mu \mathrm{L}$ de peróxido de hidrogênio $(0,38 \mathrm{M})$. Após agitação a mistura foi utilizada como padrão branco para leitura no espectrofotômetro. Em seguida, adicionou-se $25 \mu \mathrm{L}$ do extrato enzimático e registraram-se os valores da primeira leitura, sendo a segunda efetuada 2 minutos após. A determinação da atividade foi feita medindo-se a variação de absorbância a $470 \mathrm{~nm}$ da substância formada na reação enzimática (tetraguaiacol). Uma unidade de atividade foi definida como a quantidade de enzima que causou o aumento de 0,001 unidade de absorbância por minuto nas condições anteriormente citadas.

Análise dos dados - $\mathrm{O}$ delineamento experimental utilizado foi inteiramente casualizado com esquema bi-fatorial (cultivares $\mathrm{x}$ tratamentos) e seis repetições. A análise estatística dos dados foi realizada utilizando-se o programa SigmaStat 2.0 e as médias foram comparadas pelo teste de SNK $(\mathrm{P}<0,05)$.

Reação do algodoeiro à infecção por $C$. gloeosporioides var. cephalosporioides - As plantas inoculadas apresentaram sintomas típicos de ramulose nas folhas, pecíolo e hastes aos 12 dias após a inoculação, sendo menos acentuado nas cvs. Antares e Cedro e mais acentuados na cv. CNPA Precoce I.

As taxas de prolina diferiram entre os tratamentos, apresentando efeito linear ascendente nas cultivares inoculadas, com maior aumento a partir dos 15 dai, atingindo uma média de $69,5 \mu \mathrm{mol} / \mathrm{g}$ aos 30 dai. Isso representa uma diferença de $360 \%$ em relação à média do controle. A cultivar resistente BRS Antares apresentou o maior teor de prolina quando inoculada, com média de 40,8 $\mu \mathrm{mol} / \mathrm{g}$ aos 15 dias e 104, $3 \mu \mathrm{mol} / \mathrm{g}$ aos 30 dias (Tabela 1), sendo superior ao controle em 167 e $567 \%$, respectivamente.

Após reconhecimento do patógeno pela planta, ocorre a síntese de compostos anti-oxidantes que buscam diminuir os danos às células vegetais devido à ação das espécies reativas a oxigênio (ROS) sendo a prolina um desses antioxidantes (Chen \& Dickman, 2005). Na literatura, o aumento da prolina tem sido reportado como um processo de defesa das plantas contra o patógeno, cuja análise deste composto é ferramenta acessível para trabalhos de melhoramento, visando detectar plantas resistentes a este fungo. Neste trabalho os registros da concentração de prolina nas plantas foram tomados preliminarmente a partir de $48 \mathrm{~h}$, apenas nas cultivares BRS Antares e CNPA Precoce 1. Contudo, nenhuma diferença significativa foi verificada nesta fase (dados não mostrados). A partir dos três dias (72 h) observou-se uma diferença em todas as

TABELA 1 - Valores médios das concentrações de Prolina, Carboidratos solúveis e Proteínas totais em folhas de quatro cultivares de algodão aos 3, 15 e 30 dias após inoculação com Colletotrichum gossypii var. cephalosporioides

\begin{tabular}{|c|c|c|c|c|c|c|}
\hline \multirow{3}{*}{ Cultivar } & \multicolumn{6}{|c|}{ Prolina $\left(\mu{\left.\mathrm{M} . \mathrm{g}^{-1} \mathrm{MF}\right)}\right.$} \\
\hline & \multicolumn{2}{|c|}{3 dias } & \multicolumn{2}{|c|}{15 dias } & \multicolumn{2}{|c|}{30 dias } \\
\hline & C & I & $\mathrm{C}$ & I & C & I \\
\hline CNPA Precoce 1 & $22,07 \mathrm{aA}$ & $18,83 \mathrm{~dB}$ & $10,41 \mathrm{bB}$ & $34,70 \mathrm{bA}$ & $15,19 \mathrm{aB}$ & $59,55 \mathrm{bA}$ \\
\hline BRS Antares & $19,22 \mathrm{bB}$ & $28,12 \mathrm{aA}$ & $15,29 \mathrm{aB}$ & $40,83 \mathrm{aA}$ & $15,63 \mathrm{aB}$ & $104,33 \mathrm{aA}$ \\
\hline BRS $1878 \mathrm{H}$ & $18,41 \mathrm{bB}$ & $25,21 \mathrm{bA}$ & $10,44 \mathrm{bB}$ & $30,69 \mathrm{cA}$ & $15,06 \mathrm{aB}$ & $66,07 \mathrm{bA}$ \\
\hline \multirow[t]{4}{*}{ BRS Cedro } & $16,16 \mathrm{bB}$ & $21,97 \mathrm{cA}$ & $11,36 \mathrm{bB}$ & $27,72 \mathrm{cA}$ & $13,32 \mathrm{aB}$ & $64,81 \mathrm{bA}$ \\
\hline & \multicolumn{6}{|c|}{ Carboidratos $\left(\mu{\left.\mathrm{M} . \mathrm{g}^{-1} \mathrm{MF}\right)}\right.$} \\
\hline & \multicolumn{2}{|c|}{3 dias } & \multicolumn{2}{|c|}{15 dias } & \multicolumn{2}{|c|}{30 dias } \\
\hline & $\mathrm{C}$ & I & C & I & $\mathrm{C}$ & I \\
\hline CNPA Precoce 1 & $59,27 \mathrm{aA}$ & $59,79 \mathrm{abA}$ & $34,77 \mathrm{aA}$ & $37,44 \mathrm{aA}$ & $28,26 \mathrm{aA}$ & $28,73 \mathrm{bA}$ \\
\hline BRS Antares & $65,57 \mathrm{aA}$ & $73,55 \mathrm{aA}$ & $29,66 \mathrm{aB}$ & $45,94 \mathrm{aA}$ & $34,43 \mathrm{aA}$ & $34,51 \mathrm{abA}$ \\
\hline BRS $1878 \mathrm{H}$ & $59,35 \mathrm{aA}$ & $65,92 \mathrm{aA}$ & $32,29 \mathrm{aA}$ & $37,62 \mathrm{aA}$ & $28,31 \mathrm{aA}$ & $28,84 \mathrm{bA}$ \\
\hline BRS Cedro & $39,26 \mathrm{bA}$ & $50,17 \mathrm{bA}$ & $29,55 \mathrm{bB}$ & $44,80 \mathrm{aA}$ & $28,11 \mathrm{aB}$ & $40,21 \mathrm{aA}$ \\
\hline & \multicolumn{6}{|c|}{ Proteínas totais $\left(\mu{\left.\mathrm{M} . \mathrm{g}^{-1} \mathrm{MF}\right)}\right.$} \\
\hline & \multicolumn{2}{|c|}{3 dias } & \multicolumn{2}{|c|}{15 dias } & \multicolumn{2}{|c|}{30 dias } \\
\hline & $\mathbf{C}$ & $\mathbf{I}$ & $\mathbf{C}$ & I & $\mathbf{C}$ & $\mathbf{I}$ \\
\hline CNPA Precoce 1 & $1888,9 \mathrm{aA}$ & $2341,9 \mathrm{aA}$ & $1901,7 \mathrm{aB}$ & $4222,2 \mathrm{aA}$ & $2863,2 \mathrm{bB}$ & $5670,9 \mathrm{aA}$ \\
\hline BRS Antares & $2497,4 \mathrm{aA}$ & $2628,2 \mathrm{aA}$ & $2458,6 \mathrm{aB}$ & $4098,3 \mathrm{aA}$ & $4876,1 \mathrm{aA}$ & $5953,0 \mathrm{aA}$ \\
\hline BRS $1878 \mathrm{H}$ & $1778,1 \mathrm{aA}$ & $3350,4 \mathrm{aA}$ & $2072,6 \mathrm{aB}$ & $4910,3 \mathrm{aA}$ & $2363,2 \mathrm{bA}$ & $3249,7 \mathrm{bA}$ \\
\hline BRS Cedro & $2739,3 \mathrm{aA}$ & $2891,5 \mathrm{aA}$ & $2914,8 \mathrm{aB}$ & $4575,2 \mathrm{aA}$ & $3512,8 \mathrm{bA}$ & $3474,4 \mathrm{bA}$ \\
\hline
\end{tabular}

Médias seguidas de letras iguais, maiúsculas entre tratamentos e minúsculas entre cultivares, não diferem significativamente entre si pelo teste SNK $(\mathrm{P}<0,05)$. C - controle, I - Inoculado. 
cultivares inoculadas, sendo o acúmulo mais expressivo a partir dos 15 dias, quando as médias superaram mais que o dobro as registradas no controle, especialmente na cv. resistente, BRS Antares (Tabela 1). Goicoecha et al. (2000) analisaram a concentração de prolina em folhas de Capsicum annuum infectadas com o fungo Verticillium dahliae, e verificaram mais do que o triplo de acúmulo de prolina quando as plantas estavam entre 21 e 30 d.a.i. Antes disso, a concentração do aminoácido manteve-se em nível basal, nos dois tratamentos. Isso sugere que, para uso deste descritor como ferramenta discriminatória, a seleção das plantas a partir dos 15 dias após a inoculação é mais confiável e indicada na seleção de plantas resistentes.

Para os teores de carboidratos, as cultivares de algodão apresentaram basicamente a mesma reação com exceção, da BRS Cedro que diferiu em todos os períodos de avaliação quando as plantas foram submetidas à infecção (Tabela 1). Porém, as diferenças não foram grandes o suficiente para que este descritor possa ser sugerido como um caráter na identificação de plantas resistentes ou suscetíveis à ramulose. Isso deve justificar a correlação existente entre o modo de penetração dos fungos na parede celular da planta e a síntese de carboidratos. Os hospedeiros resistentes respondem a esta invasão sintetizando novos carboidratos principalmente celulose e calose. Esta deposição de açúcares solúveis pode se prolongar por um longo período até formar as chamadas papilas. Em indivíduos suscetíveis esta deposição é normalmente escassa ou inexistente (Bell et al., 1981).

Com relação aos teores de proteínas totais (PT) verificou-se aumento na maioria das cultivares inoculadas a partir dos três dias, sendo mais expressivo aos 15 dias. A partir desde período houve diferenças nas cultivares, com aumento nas cvs. BRS Antares e CNPA Precoce 1 e decréscimo nas demais (Tabela 1). Apesar do acréscimo verificado nas médias da BRS Antares aos 30 dias, nenhuma diferença estatística foi obtida entre os tratamentos. Devido a esses resultados, esse descritor, tal como para carboidratos, não é útil para discriminação de cultivares sensíveis ou resistentes à doença.

Quanto às enzimas oxidativas, observaram-se para peroxidase ( $\mathrm{POX}$ ) duas tendências com relação à sua expressão. Uma representada pelas cvs. BRS Antares e CNPA Precoce I e outra para BRS Cedro e BRS 187 8H. Nas primeiras, a resposta foi observada aos três d.a.i., com produção de $25.907 \mathrm{U} / \mathrm{mL}$ e $14.080 \mathrm{U} / \mathrm{mL}$, contra $3.840 \mathrm{U} / \mathrm{mL}$ e $2.743 \mathrm{U} / \mathrm{mL}$ no controle, respectivamente (Tabela 2). Essa diferença correspondeu a um aumento de $674 \%$ nos teores desta enzima na BRS Antares e 573\% na CNPA Precoce I. Para as cultivares BSR Cedro e BRS $1878 \mathrm{H}$, ocorreu o contrário, sendo a maior produção aos 30 dias, quando as plantas inoculadas produziram 13.920 $\mathrm{U} / \mathrm{mL}$ e $16.333 \mathrm{U} / \mathrm{mL}$, contra $5.762 \mathrm{U} / \mathrm{mL}$ e $3.333 \mathrm{U} / \mathrm{mL}$ no controle, respectivamente.

Os principais eventos da infecção ocorrem dentro das primeiras 24 h (Honty et al., 2005), mas a detecção das alterações bioquímicas nas plantas por meio das enzimas oxidativas pode ser rápida ou lenta, dependendo do patógeno e da cultura infectada. Honty et al. (2005) estudaram a atividade das enzimas peroxidase e polifenoloxidase em cultivares de pêra sensíveis e resistentes a Erwinia amylovora, às 2, 48 e 72 h após a inoculação. Dois dias após a inoculação a quantidade de enzima na cv. resistente aumentou ao longo do desenvolvimento da doença, enquanto que na sensível houve um decréscimo da POX. Campos et al. (2004) verificaram aumento de atividade da POX em plantas de feijão resistentes a C. lindemuthiamum somente a partir de 3 d.a.i. Em algodão, Dai et al. (1996) verificaram aumento de atividade da peroxidase em plantas resistentes a Xanthomonas campestris pv. malvacearu $4 \mathrm{~h}$ após a inoculação. Os altos teores de POX aqui encontrados na cv. BRS Antares atestam

TABELA 2 - Valores médios das concentrações de Peroxidase e Catalase em folhas de quatro cultivares de algodão aos 3 , 15 e 30 dias após inoculação com Colletotrichum gossypii var. cephalosporioides

\begin{tabular}{|c|c|c|c|c|c|c|}
\hline \multirow{3}{*}{ Cultivar } & \multicolumn{6}{|c|}{ Peroxidase (U/mL) } \\
\hline & \multicolumn{2}{|c|}{3 dias } & \multicolumn{2}{|c|}{15 dias } & \multicolumn{2}{|c|}{30 dias } \\
\hline & $\mathrm{C}$ & I & $\mathrm{C}$ & I & $\mathbf{C}$ & I \\
\hline CNPA Precoce 1 & $2746,7 \mathrm{bB}$ & $14080,0 \mathrm{bA}$ & $1993,3 \mathrm{bB}$ & $9906,6 \mathrm{bA}$ & $4226,6 \mathrm{aB}$ & $9106,6 \mathrm{bA}$ \\
\hline BRS Antares & $3840,0 \mathrm{bB}$ & $25906,7 \mathrm{aA}$ & $3680,0 \mathrm{abB}$ & $19026,7 \mathrm{aA}$ & $3693,3 \mathrm{aB}$ & $15346,6 \mathrm{aA}$ \\
\hline BRS $1878 \mathrm{H}$ & $1780,6 \mathrm{bB}$ & $10813,3 \mathrm{bA}$ & $3506,7 \mathrm{abB}$ & $15880,0 \mathrm{aA}$ & $3333,3 \mathrm{aB}$ & $16333,3 \mathrm{aA}$ \\
\hline \multirow[t]{4}{*}{ BRS Cedro } & $7936,0 \mathrm{aB}$ & $11626,7 \mathrm{bA}$ & $6680,0 \mathrm{aB}$ & $12546,7 \mathrm{bA}$ & $5762,2 \mathrm{aB}$ & $13920,0 \mathrm{aA}$ \\
\hline & \multicolumn{6}{|c|}{ Catalase } \\
\hline & \multicolumn{2}{|c|}{3 dias } & \multicolumn{2}{|c|}{15 dias } & \multicolumn{2}{|c|}{30 dias } \\
\hline & $\mathbf{C}$ & I & $\bar{C}$ & I & $\mathbf{C}$ & I \\
\hline CNPA Precoce 1 & $3093,3 \mathrm{bcB}$ & $11586,7 \mathrm{cA}$ & $2450,0 \mathrm{aB}$ & $7146,6 \mathrm{bA}$ & $1386,6 \mathrm{aA}$ & $1173,3 \mathrm{aA}$ \\
\hline BRS Antares & $4638,7 \mathrm{abB}$ & $22466,7 \mathrm{aA}$ & $1824,0 \mathrm{aA}$ & $1706,6 \mathrm{cA}$ & $1853,3 \mathrm{aA}$ & $1693,3 \mathrm{aA}$ \\
\hline BRS $1878 \mathrm{H}$ & $2093,3 \mathrm{cB}$ & $9520,0 \mathrm{dA}$ & $1440,0 \mathrm{aA}$ & $1360,0 \mathrm{cA}$ & $1460,0 \mathrm{aA}$ & $1293,3 \mathrm{aA}$ \\
\hline BRS Cedro & $5600,0 \mathrm{aB}$ & $15426,7 \mathrm{bA}$ & $1933,3 \mathrm{aB}$ & $11386,6 \mathrm{aA}$ & $533,3 \mathrm{bA}$ & $880,0 \mathrm{aA}$ \\
\hline
\end{tabular}

Médias seguidas de letras iguais, maiúsculas entre tratamentos e minúsculas entre cultivares, não diferem significativamente entre si pelo teste SNK $(\mathrm{P}<0,05)$. $\mathrm{C}$ - controle, I - Inoculado. 
sua condição de resistência à ramulose sendo, portanto, um relevante recurso genético a ser utilizado em trabalhos de melhoramento para transferência de resistência a esta doença.

Quanto à catalase, verificou-se maior produção no início da infecção e queda a partir dos 15 dai (Tabela 2). As cvs. BRS Antares e BRS Cedro apresentaram $4.638 \mathrm{U} / \mathrm{mL}$ e $5.600 \mathrm{U} / \mathrm{mL}$ nas plantas controle aos 3 dai, respectivamente. Quando infectadas, os níveis foram elevados para 22.467 $\mathrm{U} / \mathrm{mL}$ e $15.427 \mathrm{U} / \mathrm{mL}$, superando os valores encontrados nas cultivares suscetíveis em ambas as situações. De acordo com Kuzniak \& Sklodowska (2005) e Luhová et al. (2006), os teores elevados de catalase servem como indicador da resposta da planta à infecção, sendo frequentemente mais elevado na planta resistente, no inicio da infecção.

Em trabalhos convencionais de melhoramento de plantas, geralmente, todo procedimento é baseado em descritores fenotípicos, obtidos por meio de inoculação de plantas com o patógeno. A possibilidade de seleção de genótipos resistentes por meio de descritores bioquímicos confiáveis abre perspectivas para auxiliar nos processos de seleção, apresentando ainda a vantagem de redução de custo e de tempo na identificação de acessos resistentes. Apesar de não ter sido encontrada relação direta quanto ao teor de carboidratos e de proteínas na distinção das cultivares resistentes ou suscetíveis de algodoeiro, os resultados obtidos com a prolina e as enzimas peroxidase e catalase foram expressivos e confirmam sua associação com a resposta de defesa da planta ao patógeno.

\section{AGRADECIMENTOS}

Os autores agradecem a Embrapa Algodão e a Financiadora de Estudos e Projetos - FINEP pelo apoio financeiro, e a Coordenação de Aperfeiçoamento de Pessoal de Nível Superior - CAPES pela concessão da bolsa de Mestrado.

\section{REFERENCIAS BIBLIOGRÁFICAS}

Bates LS, Waldren RP, Teare ID (1973) Rapid determination of free proline for water-stress studies. Plant and Soil 39:205-207.

Beers RF, Sizer IW (1952) A spectrophotometric method for measuring the Breakdown of hydrogen peroxide by catalase. The Journal of Biological Chemistry 195:133-140.

Bell AA (1981) Biochemical mechanisms of disease resistance. Annual Review of Plant Physiology 32:21-81.

Bradford MM (1976) A rapid and sensitive method for the quantification of microgram quantities of protein utilizing the principle of protein-dye binding. Analytical Biochemistry 72:246254.

Campos AD, Ferreira AG, Hampe MMV, Antunes IF, Brancão N, Silveira EP, Osório VA, Augustin E (2004) Atividade de peroxidase e polifenoloxidase na resistência do feijão à antracnose. Pesquisa Agropecuária Brasileira 39:637-643.

Chen C, Dickman MB (2005) Proline suppresses apoptosis in the fungal pathogen Colletotrichum trifolii. Proceedings of the National Academy of Sciences 102:3459-3464.

Dai GH, Nicole M, Andary C, Martinez C, Bresson E, Boher B, Daniel JF, Geiger JP (1996) Flavonoids accumulate in cell walls, middle lamellae and callose-rich papillae during an incompatible interaction between Xanthomonas campestris pv. malvacearum and cotton. Physiological and Molecular Plant Pathology 49:285306.

Dann EK, Deverall BJ (2000) Activation of systemic disease resistance in pea by an avirulent bacterium or benzothiadiazole, but not by a fungal leaf spot pathogen. Plant Pathology 49:324332.

Dubois M, Gilles KA, Hamilton JK, Rebers PA, Smith F (1956) Colorimetric method for determination of sugars and related substances. Analytical Chemistry 28:350-356.

Freire EC (2007) Algodão no Cerrado do Brasil. Cap. 1. Brasília DF. Associação Brasileira dos Produtores de Algodão ABRAPA. pp. 21-52.

Goicoechea N, Aguirreolea J, Cenoz S, García-Mina JM (2000) Verticillium dahliae modifies the concentrations of proline, soluble sugars, starch, soluble protein and abscisic acid in pepper plants. European Journal of Plant Pathology 106:19-25.

Honty K, Hevesi M, Tóth ME, Stefanovits-Bányai E (2005) Some biochemical changes in pear fruit tissue induced by Erwinia amylovora. Acta Biologica Szegediensis 49:127-129.

Kuzniak E, Sklodowska M (2005) Fungal pathogen-induced changes in the antioxidant systems of leaf peroxisomes from infected tomato plants. Planta 222:192-200.

Luhová L, Lebeda A, Kutrová E, Hedererová D, Peč P (2006) Peroxidase, catalase, amine oxidase and acid phosphatase activities in Pisum sativum during infection with Fusarium oxysporum and F. solani. Biologia Plantarum 50:675-682.

Mehta YR, Zandoná C, Bibanco K, Almeida WP, Teixeira EA, Cunha HC, Erivaldo J (2005) Resposta diferencial de cultivares comerciais do algodoeiro a Colletotrichum gossypii var. cephalosporioides. Summa Phytopathologica 31:142-145.

Scarpari LM, Meinhardt LW, Mazzafera P, Pomella AWV, Schiavinato MA, Cascardo JCM, Pereira GAG (2005) Biochemical changes during the development of witches broom: the most important disease of cocoa in Brazil caused by Crinipellis perniciosa. Journal of Experimental Botany 56:865-877.

Zandoná C, Novaes TG, Mehta YR, Schuster I, Teixeira EA, Cunha H (2006) Herança de resistência a Colletotrichum gossypii var. cephalosporioides em algodoeiro brasileiro. Fitopatologia Brasileira 31:76-78. 